\title{
Equal Protection by Race with Stop and Frisk: a Risk-Adjusted Disparity (RAD) Index for Balanced Policing
}

\author{
Lawrence W. Sherman ${ }^{1}$ (D) $\cdot$ Sumit Kumar $^{1}$ (D)
}

Published online: 6 July 2021

(C) The Author(s) 2021

\section{Abstract}

Research Question Can racial equity in crime and policing be measured with the use of a Risk-Adjusted Disparity (RAD) Index of the degree to which policing across racial categories is "balanced" in its ratios of preventive police actions per 100 serious crimes committed against members of each racial category?

Data Office of National Statistics (ONS) reports on crime and policing in England and Wales, and Dorset Police data on violent crime victimization and stop-search by race of suspect across the 452 Lower-Layer Super-Output Levels in Dorset.

Methods We conceptualize the problem of equal protection under law as fundamentally protecting the lives and liberties of each citizen from criminal harms, as well as from disproportionately intrusive policing. We combine these dimensions into a single metric that defines proportionality of policing in relation to risk of violent crime victimization, such that whatever intrusion on liberty is applied for the aim of protection can be equalized across racial groups.

Findings The use of a Risk-Adjusted Disparity (RAD) Index to measure reliably the equality of police intrusions across racial groups based on victimization rates can be illustrated by adjusting for homicide. In the past decade, the population-based disparity rate shows that Blacks are stopped by police nine times more often than whites. When that rate is adjusted for the differential risk of homicide in the two groups, the disparity estimate drops from $800 \%$ to $58 \%$. Other changes of major magnitude result from using the RAD Index.

Conclusions We conclude that an index of proactive policing using victimizations by race is more likely to lead to equal protection of law than a residential population-based

Lawrence W. Sherman

Lawrence.Sherman@crim.cam.ac.uk

1 Jerry Lee Centre for Experimental Criminology, Institute of Criminology, University of Cambridge and Cambridge Centre for Evidence-Based Policing Ltd., Cambridge, UK 
metric of proactive police actions, as is commonly used in official reporting. A victimbased, Risk-Adjusted (RAD) Index for measuring racial disparity might focus police efforts on the $5 \%$ of local areas where serious violence is concentrated, and deflect stops away from the vast majority of areas that have little serious crime.

Keywords Race $\cdot$ Policing $\cdot$ Index $\cdot$ Violence $\cdot$ Stop and search $\cdot$ Over-policing $\cdot$ Underpolicing $\cdot$ Balanced policing $\cdot$ Risk-Adjusted Disparity (RAD) Index

\section{Summary: Racially Balanced Policing and the RAD Index}

How can racially balanced policing be operationally defined for the purposes of measurement and tracking of police actions? In current public discourse, "over-policing" is often measured in relation to police actions per capita against different racial groups. Yet the idea of "equal protection" arguably requires a measure of equal police actions per crime (or victimizations) against people of different races, so that police can provide equal resources by race even when victimization rates differ.

Homicide rates, for example, are five times higher for Blacks than for Whites in both the USA (Reiss and Roth 1993) and the UK (Kumar et al. 2020). This disparity suggests that, by definition, a state of "under-policing" exists in the protection of Blacks relative to Whites, as measured on the basis of risk. This imbalanced policing could use evidence-based methods to reduce Black homicide victimizations by allocating greater resources to communities at greater risk of murders. If the result of better resource allocation was equalization of homicide outcomes, the strategy could be described as neither "over" nor "under" policing, but "balanced policing." This concept would seem appropriate to describe communities in which police resources are allocated in equal proportions based on unequal risk and harm, even if different rates of policing actions persist between races.

Risk-Adjusted Disparity (RAD) Index From this perspective of equal protection from unequal risk, measuring the racial balance of preventive policing can be calculated from a Risk-Adjusted Disparity (RAD) Index. In that index, the denominator would always be a measure of crime or harm per capita in each group; the numerator would be a measure of police action. Disparities in proactive police activities, such as stop and search or patrol time, could therefore be adjusted by the racial disparities in criminal victimization that preventive policing aims to equalize. What might look like disparities in policing against certain groups would then be understood as an equalizing intervention to reduce disparities in victimization across groups.

Why a Victim Denominator Rather Than Full Population? The population in greatest need of protection from violent crime is not reliably measured by the resident population of a community as measured by a decennial Census. Many age and gender groups within and across racial categories have extremely low rates of victimization by violence, providing little inequality in protection under law (Kumar et al. 2020, 2021). Young males, in contrast to older people of both genders, spend more time on the streets and in the hot spots where serious violence is most likely to occur (Skogan and Frydl 2004; Weisburd 2015). Using local residential populations is also an 
unreliable measure of denominator populations at risk of violent crime in entertainment areas.

Why Victims Rather Than Offenders? The measurement of demographic characteristics of offenders is unreliable due to low detection rates, which are far fewer in number than reported victimizations. Even though self-reported race or ethnicity by victims is often left blank in police crime reports in the UK, that measure provides a more robust and comprehensive description of the population suffering unequal protection of the law by higher harm from violence. In addition, there is enormous overlap between victims and offenders in violent crime in England (Sandall et al. 2018), Canada (Hiltz et al. 2020), and the USA (Reiss and Roth 1993). A victim today could be a victim tomorrow, and even violent offenders generally suffer more crime harm than they cause (at least in official records). Using victims as a denominator also seems to be a less provocative and more legitimate strategy in light of a widely documented history of over-policing of racial minorities in many nations.

Operational Implications Police agencies can use a RAD Index to track racial balance in policing on a weekly basis, to inform police and public of the results, and to take corrective action as needed to foster more equal victimization rates. They can do this, in principle, at the same time that they can also undertake to intensify preventive policing efforts in the small proportion of all public places in which the vast majority of crime harm from violence occurs. By limiting most stop and search encounters to those areas at greatest risk of (unequal) violence, they can follow the principle of proportionality implied by the Hippocratic Oath (Sherman 2018; Gladwell 2019).

\section{Equal Protection and Unequal Risks of Crime}

Liberal democracies are rightly committed to the principle of equal protection under law for all people, regardless of their individual characteristics. Yet there is substantial ambiguity in public understanding of equal protection from the law imposing penalties unfairly, or equal protection by the law from crime being committed at higher rates against some people than others. Arguably, both kinds of protection should be equal. Yet unequal crime can cause an appearance of unequal justice.

The major challenge of policing to foster equal protection by the law is the unequal distribution of risks of criminal victimization, shaped by societally systemic racism and persisting social inequalities (e.g., Unnever et al. 2021). In order for policing to define equal protection as the "destruction of illegitimate hierarchies" (Sklansky 2004, 2008) in the risk of harm, it must prioritize crime prevention resources where risks are highest - especially for any racial or ethnic disparities in the probability of individuals in different groups suffering death or harm from crime. In pursuit of equal protection against unequal risk of harm, it is logically necessary that police adopt unequal allocation of police resources to compensate for historical disadvantages. Such historically compensatory inequality is a widely used, if hotly debated, strategy for equalizing contemporary life chances. 
Fair vs. Proportionate Policing The demand for a state of more balanced policing is easily confused with a demand for less crime and harm. Yet racial balance and societal violent crime rates are not the same thing. Balanced policing can only be based on a measure of fairness. It cannot be measured, by definition, by the effectiveness of policing in crime prevention. The questions of how much or what kinds of policing are needed to reduce crime nationally, or in any single neighborhood, are independent of the principles of equal protection from a national crime rate.

Balanced policing could therefore be achieved even in high-crime communities, where total police resources may be woefully inadequate for the job at hand. That inadequacy would be lacking in societal "proportionality" of resources to harm, but the inadequacy could still be racially fair and balanced. The definition of balance is not that crime is controlled; balance is a state in which police intrusions of liberty are applied equally across racial groups in a consistent ratio to the same measures of risk and harm- especially where that risk differs by race.

Balanced policing can only be attained with such clearly defined concepts. Such clarity is in short supply, although some political dialogue has succeeded in separating the very different ideas of fairness and proportionality. In the 2019 UK elections, for example, the winning party promised to support more police use of stop and search with a dual requirement:

"We will empower the police, backing the increased use of stop and search as long as it is fair and proportionate"1

Fairness If stop and search is to be fair, the standard is not the degree of equality in its application per person, since not all persons are equally at risk from crime. Fairness in crime prevention requires equal application per crime of the crime types in any location that justify any level of intrusion into liberty (Home Office 2014). Even if that intrusion is perfectly balanced across population counts, it may still be unfair across victimization-by-race counts.

Proportionality Whether the harmfulness of stop and search is proportionate to the harm it is intended to prevent is an entirely separate question. Stop and search is seen by many to be an intrusion on liberty so severe that it can be proportionate only to a high risk of high harm. Wherever or whenever such high risk is lacking, stop and search can be said to be disproportionately harmful (as in Hippocrates' principle of limiting harm in medicine). If, for example, stop and search was used frequently in a car parking area of a national park-where no history of violent crime had ever been documented-one could claim that the tactic was disproportionately harmful (or excessive) in relation to the risk in that place. That would be true even if fairness was guaranteed by search $100 \%$ of hikers of all races. One observer (Gladwell 2019) even makes a strong case that stop and search should only be used in areas of high violence, where it has been shown to be effective.

Feelings and Facts of Fairness However logical this analysis may be, it is unpersuasive unless it also "feels" fair. The sustainability of this, or any, strategy based on logic and evidence in a democracy may depend as much on its perceived legitimacy as on its

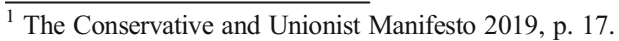


demonstrated necessity. Logic in this task, as ever, must be bolstered by sentiment, or at least familiarity. For the latter, we can look to precedent.

In some contexts, the legitimacy of unequal resource allocation per person is readily accepted when it is based on elevated risk. Personal bodyguards for US Presidents and UK Prime Ministers, for example, are readily accepted as required by the very high risks of murder committed against national leaders. The murder victimization rate for the 46 US Presidents (four shot dead), for example, is $8.7 \%$, or 1717 per 100,000 President-years across the 233 years in 1789-2021, compared to annual US population rates of 5 to 10 per 100,000 person-years. In other words, Presidents suffer a risk of homicide that is roughly 170 times higher than that of the people who elect them (and 1700 times the murder rate of English residents). The massive cost of protecting Presidents, ex-presidents, and their families therefore "feels" justified by their massively high level of risk.

Yet seen from the viewpoint of Presidents protected, the cost of constant protection feels like a massive intrusion on their liberty. People protected by bodyguardsincluding Presidents - often complain about the intrusiveness of their protection, and the loss of their rights to privacy. They accept the intrusions on the logic of the "no pain, no gain" principle of exercise, which fits the dilemma of murder prevention: there is no way to protect against such presidential murders without the often annoying presence of the presidential protectors.

While few may feel sympathy for inconvenienced VIPs, many people feel angry at the idea of "over-policing" demographic groups that are socially disadvantaged. Disparities in police stopping or arresting Whites and non-Whites often feel inherently unfair. That sentiment poses a challenge to the very idea of allocating more police time and activity to protect potential victims of the same racial group. Those concerns are magnified by the history of systemic racism in law enforcement, as well by contemporary patterns of higher imprisonment rates and (in the USA) higher fatal shootings by police of minorities than Whites (Zimring 2017).

The most powerful emotional foundation for balanced policing may therefore be the reality of far higher murder rates for Blacks than Whites (Kumar et al. 2020). Parents of murder victims, especially in the UK, have often made a case for more policing - and specifically stop and search to prevent murder (e.g., Simpson 2020). It may be possible to reinforce their demands with more evidence-based definitions of key concepts.

\section{Over-policing and Under-policing}

Colloquial use of the concept of "over-policing" implicitly defines it as any disparity in the intrusiveness of policing across categories of people or places. Yet if policing is equal across unequal risks, a lack of disparity in police attention across groups at different risk levels could be defined as "under-policing." That is, if police fail to allocate resources with a metric that is proportionate to differences in risk, they could be failing to perform their duty to create equal protection. In between these two extremes, there is an implied state of "balanced policing." But how would that balance be defined?

We know that the 14th Amendment to the US Constitution failed to achieve balanced policing in the history of under-policing African-American areas in the 
USA, a story rife with police refusal to provide services in those areas (Wilson 1978: 149-50). Similarly, the thin layer of bodyguard protection for US Presidents from Lincoln to Truman can be seen as unbalanced, under-policing. Similarly, the 6th January 2021 failure of the United States Capitol Police (USCP) to protect against the well-documented risk of invasion of a sitting legislature by a violent mob was seen as a shameful case of under-policing, as the USCP Chief later admitted (Demirjian et al. 2021).

Victimization-Based Disparities Disparities in policing across highly disparate crime rates are a logically necessary corollary of balanced policing for equalizing protection from crime by targeting victimization rates. The measurement of "balance" should be therefore calculated by the extent of disparities between victimization per capita, or by intrusions on liberty relative to risk, across places, areas, or racial and ethnic groups.

The implicit assumption of the "under vs. over" policing terminology is that a state of balanced policing occurs when disparities in police practice are balanced in relation to disparities in risks of harm. Such balance could be defined, empirically, as a state of equal protection under law, in which no measureable or vulnerable group suffers substantially higher risks of harm from crime than any other without proportionate attempts by police to reduce those elevated risks.

In practice, a community of equal crime risks across demographic groups may be difficult for any institution to achieve in ways that are measured by crime victimization rates. Yet a goal of balanced policing may be highly achievable if it is defined in relation to measuring disparity in police intrusiveness that makes appropriate adjustments for the disparity in risk - the greater the risk, the greater the need for police to do more to reduce the risk. This imperative can be measured, in ways that create transparent evidence of efforts to provide equal protection. The purpose of what follows is to introduce and illustrate the concept of a Risk-Adjusted Disparity (RAD) Index as a tool for tracking police practices.

\section{Stop and Search: a Case for "Balanced" Policing}

Across the English-speaking world, the prime case in point for using a RAD Index to address this dilemma is the police practice of stop and search. This issue cannot be adequately addressed without a clear position on the potential of stop and search for reducing serious violence, a potential which many deny. The ongoing debate about the effectiveness of that practice does not negate the evidence recently summarized by a (U.S.) National Academies of Science committee (Weisburd 2018 eds.: 310):

"CONCLUSION 4-9 Evaluations of focused uses of stop, question, and frisk (SQF) (combined with other self-initiated enforcement activities by officers), targeting places with violence or serious gun crimes and focusing on high-risk repeat offenders, consistently report short-term crime-reduction effects..."

While there are observational studies which claim to find no link between stopsearch volume and overall crime, or even violent crime, the National Academies of Science report went on to note (Weisburd \& Majmunder eds. 2017:311) that

"Non-experimental analyses of SQF broadly applied across a jurisdiction show mixed findings. However, a separate body of controlled evaluation research (including 
randomized experiments) that examines the effectiveness of SQF and other selfinitiated enforcement activities by officers in targeting places with serious gun crime problems and focusing on high risk repeat offenders consistently reports statistically significant short-term crime reductions."

Given good (if contested) reasons to use stop and search to reduce serious violent crime in high-risk places, police have often allocated more resources for using that practice for that purpose. Sadly, police have also used stop and search in low-crime contexts in which there is no potential to reduce inequalities in criminal victimization (Gladwell 2019: 309-312). This pattern, across the USA, creates three problems. One is disproportionality, in which there is a level of intrusion that is disproportionately higher than the level of harm that the police intrusion might prevent. A second is unfairness, in which the disproportionate police conduct is allocated at a higher rate across a jurisdiction to non-Whites than to Whites. The third is ineffectiveness, or a jurisdiction suffering higher levels of crime harm than it would if resources (such as stop and search) were concentrated in the places where crime harm is most concentrated. Stopping minorities at disparately higher rates than whites, in low crime areas, is therefore disproportionate, unfair, and ineffective.

Indeed, much of the controversy about stop and search may be due to "de-coupling" the use of such an intrusive tactic from the locations of the high-harm problems that justifies and legitimates that tactic (Sherman, forthcoming). Where policing is seen to respond in a way that is proportionate to local needs, such as the aftermath of a murder, the legitimacy of that decision is rarely questioned. The challenge is to create police legitimacy for prevention of murders, not just for reactive responses provided after it is too late to prevent.

It is important, of course, that police create total transparency about the use of stop-and-search. It is equally important, however, to create transparency about how the use of that practice relates to the aim of reducing demographic inequalities of victimization. Focusing merely on disparities in policing, absent any context of disparities in victimization to be rectified, undermines not only trust and confidence in the police. It may also undermine rational and proportionate efforts to provide equal protection under law.

Neither the USA, nor (apparently) any other country, reports ongoing statistics on stop and search by police in direct relation to risks of murder or serious violence. What is most transparent for many police agencies is the racial disparity in risks of pedestrians (or drivers) being stopped. These reports consistently show that members of minority groups are more likely to be stopped by police than members of majority groups. These data are a useful start. Yet they lack any reference to risk of crime harm. The result may be to limit police tools for preventing serious violent crime.

In the wake of global outrage over the killing of George Floyd in mid-2020, three out of four US residents polled said that stop and search should be banned altogether (Crabtree 2020). One open question is whether that opinion could change if statistics showed that police stops were conducted in a balanced way, as measured by a RiskAdjusted Disparity (RAD) Index. The prior question, and focus of this discussion, is whether policing could use a RAD Index to track and transform current practice, thus creating more balanced policing for statistics to report. 


\section{Statistics Taken Out of Context}

Like a quotation of a single phrase out of a larger sentence that changes the meaning of the phrase, statistics taken out of context can be equally misleading. In the case of stop and search, this is clearly the case for the current statistical reporting protocol.

The UK Office of Office of National Statistics, United Kingdom (2020) recently published this table for rates of stop and search in England and Wales per 1000 persons, by ethnicity (ONS 2020 SS.12) (Table 1):

In the most recent year available, the Office of National Statistics (ONS) data show that the rate per 1000 at which Black people were stopped was nine (9) times higher than the rate at which Whites were stopped $(54 / 6=9)$. This disparity, understandably, has been read by many as evidence of a lack of fair practices by police, and criticized by many observers.

Yet as Kumar and colleagues (2020: Fig. 1) recently reported in the Cambridge Journal of Evidence-Based Policing, the risk levels for homicide victimization of Black people in England and Wales are also much higher than they are for White residents of the UK. For people in the age range of 16-24, which encompasses a substantial portion of all stops, the difference in homicide victimization rates is twenty-four (24) times higher for Blacks than for Whites.

Taking these facts together puts them in a very different context, with a very different meaning. Rather than evidence of over-policing of Black people, the data may suggest under-policing of Blacks relative to Whites, at least in some communities, as measured by stop and search encounters per 100 murder victims by ethnicity. Simply comparing policing practices by ethnicity, as some news media have done, implies that stops are isolated from crime victimization risks in space, in time, and across demographic groups. The premise of evidence-based policing, as well as evidence-based public health, is that scarce resources are best targeted selectively on cases with highest risks of high harm, among places, victims, and offenders.

While the idea of adjusting police activity based on risk of victimization has not been controversial in the abstract, it may well become controversial in relation to race. After some 9000 readings of the Kumar et al. (2020) article, for example, the most common question from readers was "what is the race of the murderers." That question tends to miss the point, or several points:

1. Official records provide data on the characteristics of all known murder victims, but the same is not true for offenders. Depending on the year and location, the ethnicity of murderers is missing information for up to $50 \%$ or more murder cases in the UK (and a far higher percentage in some US cities). Thus while victimization rates are reliably measured by ethnicity and location of residence, offending rates are not.

2. To the extent that samples with high detection rates of murders victims have examined the issue, offenders tend to resemble each other in age, gender, and ethnicity, as well as geography of residence (Wolfgang 1958; Reiss and Roth 1993).

3. In violent confrontations, moreover, who ends up as a victim and who does not may be a matter of chance, especially when weapons are present. Victim characteristics may therefore be the best indicator for police to decide where their use of 
stop and search may have the greatest benefit in preventing serious violence (Lattimore et al. 1997).

4. In repeated studies, a risk-focused approach to targeting areas or people with high rates of serious violence has been able to ignore the issue of ethnic characteristics and simply rely on criminal events (Sherman et al. 1989; Massey et al. 2019; Campana and Giovanetti 2020). If there is an ethnic disparity in stop and search that is derived from the geographic distribution of homicide risk that is linked to ethnic population concentrations, the disparity may thus be a statistical corollary of the worthy goal of homicide prevention.

In sum, one direct indicator of risk of homicide or serious violence is the prior occurrence of such crimes at micro-local places. Race or ethnicity need have nothing to do with the targeting and assignment of proactive police patrols to such places. If police leaders assign too few resources, including stop and search, to micro-places that have high rates of serious violence, we have suggested that such practice is "underpolicing" of those places - just as they could be said to be "over-policing" micro-places that have more stop and search delivery than the recent risk of serious violence would indicate.

A risk-based analysis of over-or-under-policing by location corresponds directly to resource allocations in other areas of governance, such as allocating

- COVID vaccines scheduling first to those most at risk of death

- Free school lunches to students most at risk of malnutrition

- Restrictions on travel to and from countries with highest infection rates

While these examples are themselves not without controversy, they all show how a focus on risk and harm can redefine the concept of equal protection and "overpolicing," especially for the prevention of serious injury. How, then, could this approach be applied in policing, if only as a check on fairness and effectiveness of resource allocation? And, crucially, how can the disparity in stops of individuals be adjusted when police are targeting proactive stop-and-search by geographic units of analysis.

\section{A Risk-Adjusted Disparity (RAD) Index}

If we take stop and search as a prime example of tracking over-policing or underpolicing in relation to risk, we can illustrate these key parameters for measuring what matters with a "Risk-Adjusted Disparity" (RAD) Index. This index can be calculated nationally, by race, as in the first example below. More usefully, they can be calculated by local places. At both national and local levels, the RAD Index can thus be calculated as the extent to which the ratio of stops per 100 serious crimes is similar or different between any two demographic groups. The basic metric is a ratio of ratios, between the stops of persons in one group (per 100 crimes against persons in that group) in ratio to the same metric of stops per 100 crimes against persons in another group. The index is constructed to be interpreted as follows: 
The higher the Index value is over 1:1, the greater the over-policing of any minority group in relation to risk of victimisation. The two numbers are derived by the first number representing policing of a minority group per 100 crimes against them, and the second number representing policing of a majority group per 100 crimes against them.

This is how the RAD can be calculated.

1. Any minority demographic group experiencing the intrusions of stop and search $(\mathrm{S} \& S)$ police encounters intended to prevent crime can have its stops measured as a frequency per 1000 residents of that group, within a location of any measurable boundaries.

2. The rate of police intrusions per 1000 minority persons can be divided by the rate of serious violent crime (SVC) victimizations per 1000 persons, also by location, in the same boundaries.

3. The rate in (1.) above can then be divided by the rate in (2.), to produce a ratio of rates for minority residents.

4. The first 3 steps can be repeated for local majority population residents, to produce a ratio of rates for majority residents.

5. Then in any location, the ratio of the minority to majority rates can vary upwards or downwards from a midpoint of 1:1, with the two sides being equal, or one group being over-policed relative to the other. Given the problem of small numbers in small places, however, a threshold of clarity between "over" and "under" would need to be set, such as a rate per 1000 being three times higher or lower in group A relative to group $\mathrm{B}$ - with the ratios in between that range considered an area of uncertainty.

Example I At the national level across England and Wales, Kumar et al. report that the ratio of murders to 100,000 population in 2010-2019 for Blacks was a mean of 3.46, while for whites it was a mean of 0.92 murders per 100,000 . That national Black-White murder ratio of 3.76 to 1 is the challenge police face in trying to achieve equal protection. In the same time period, the mean annual rate of stop and search per 100,000 Blacks was 5600 , compared to 940 stops per 100,000 whites - a ratio of 5.96 to 1 . But if we divide the 5600 black stops per 100,000 by the 3.46 murders per 100,000 , the stops to murders ratio for Blacks is 1618 . The comparable number for Whites is 1022 .

The RAD Index is then 1618 (Blacks)/1022 (Whites) $=1.58$ to 1 .

This means that while the RAD Index is not zero, the level of 1.58 to 1 is nowhere near as high as the population-based racial disparity rate, which was 9 to 1 in 2019 (see Table 1).

This example is only meant to illustrate the difference in magnitude. This does not imply a valid basis for a standard of police stop and search against all murders, many of which are domestic and occur off the streets where stops can occur. But if a murder occurs at an indoor party, committed with a knife the murderer carried illegally through the streets, the ratio of stops per murders (or serious violent crimes) by area is not irrelevant. Hence, the best use of the RAD Index is likely to be found at the local level, as in the next example. 
Example II In Dorset, there is a Lower-Layer Super Output Area (LSOA) in which the following data were observed for the 4-year period of 2016-2019:

Resident population $(2011$ Census $)=1531$ Whites and 135 non-Whites

1. White population rate per 1000 of stop and search (3.25)

2. White rate per 1000 of serious violent crime victimization $=2.75$.

3. Ratio of White rates $=3.25 / 2.75=1.18: 1$ (for every serious violent crime against Whites, there were 1.18 stop and search encounters with Whites).

4. Repeat for non-Whites:

a. Non-White population rates per 1000 of stop and search $=.25$

b. Non-White population rate of serious violent crimes 2.75

c. Ratio of non-White rates $=.25 / 2.75=0.9$

5. Ratio of ratios: non-White (0.09) to White $(1.18)=0.08$

Therefore, in that LSOA, the likelihood of Whites being stopped and searched is 13 times higher $(1.18 / 0.09=13)$ per serious violent crime against Whites than it is for nonWhites. In that case, there would be more suggestive evidence of under-policing nonWhite residents than there would be of over-policing them. Yet in that area, the rate of serious violent crime against non-Whites was about $15 \%$ lower per 1000 non-White residents than the rate of SVC against Whites per 1000 White residents. Given the small numbers on which the rates are based, however, the range of error would encompass both rates, so that the example would suggest racial equality in riskadjusted stop and search.

\section{Applying the RAD Index to Operations}

The complexity of this problem cannot be solved by a mere calculation, no matter how well publicized the RAD Index results may be (as a contrast to population-based rates). While the RAD Index may protect against misleading conclusions about racial prejudice, it is not sufficient to manage the risk of stop and search, or of other highly intrusive police practices.

Another option might take a different premise: that in most areas, police stops are too intrusive to be used at all. In any area with few serious violent crimes per capita, stops could basically be declared unavailable absent clear exceptions. With a threshold question of how much serious violence is needed to make the intrusiveness of stop and search a response that is proportionate to the crime harm, the RAD Index calculations might not even be necessary in most local areas in most cities and most countries (Gladwell 2019; Sherman "Three Tiers" forthcoming). Simply put, the most direct path to policing perceived to be fairer is to effectively limit proactive stops outside of highviolence hot spots.

In most areas, which lack enough serious crime to justify the intrusion of stop and search, stops could be limited to extraordinary circumstances. They might also be conducted only with prior approval of a high-ranking officer reached by radio. The utility of the RAD Index would then be concentrated on the high-violence hot spots. 
That would also focus the analytic systems needed to track and correct any demographic imbalances in policing. The question is where and how to set the threshold.

\section{Threshold Levels for "Tiered" Policing}

The simplicity of limiting police stops to very high crime micro-locations is heavily evidence-based. Weisburd (2015) shows how small a fraction of all locations accounts for a majority of all crime. Weinborn (2017) showed that an even smaller portion of Birmingham UK accounted for a majority of crime harm index weight (Sherman forthcoming) values, most of which reflected serious violent crimes. Moreover, evidence on the value of stops in reducing crime is limited to tests in areas of extremely high violence areas. There is no logical reason, nor evidence, to expect that stop and search can deter serious violence where it virtually never occurs, such as Dorset in the UK or even in Seattle in the USA.

One way to define such hot spots is by reference to a national standard, such as that in England and Wales, which can at least be used to compute average annual levels of violent crimes per Lower Super Output Area (roughly equivalent to Census Tracts in the USA). Table 2 shows how this can be done. It displays the data from the most recent year available (2019) for the total numbers of police stops (including Section 1, Section 60, and Section 44/47 A), Serious Violent Crimes, and Lower Super Output Areas. It also displays relevant means and rates. The data are useful for considering an answer to the question of what threshold is reasonable for how much serious violence is needed to make the intrusiveness of stop and search a response that is proportionate to the crime harm.

At a mean of 21 violent crimes per year per LSOA, there would be one violent crime every 18 days, or around one such crime every 2 weeks in a population of about 1500

Table 1 Stop and searches ${ }^{1,2}$ per 1000 population, by ethnicity ${ }^{3}$, England and Wales ${ }^{4}, 2010 / 11$ to 2019/20

\begin{tabular}{|c|c|c|c|c|c|c|}
\hline \multirow[t]{3}{*}{$\begin{array}{l}\text { Rates per } 1000 \\
\text { population }\end{array}$} & & & & & & $\begin{array}{l}\text { England and } \\
\text { Wales }\end{array}$ \\
\hline & \multicolumn{6}{|c|}{ Self-defined ethnicity } \\
\hline & White & $\begin{array}{l}\text { Black (or Black } \\
\text { British) }\end{array}$ & $\begin{array}{l}\text { Asian (or Asian } \\
\text { British) }\end{array}$ & $\begin{array}{l}\text { Other Ethnic } \\
\text { Group }\end{array}$ & Mixed & $\begin{array}{r}\text { All BME } \\
\text { groups }\end{array}$ \\
\hline $2010 / 11$ & 17 & 115 & 35 & 28 & 31 & 53 \\
\hline $2011 / 12$ & 16 & 98 & 31 & 24 & 29 & 46 \\
\hline $2012 / 13$ & 15 & 67 & 23 & 19 & 24 & 33 \\
\hline $2013 / 14$ & 13 & 56 & 18 & 17 & 20 & 28 \\
\hline $2014 / 15$ & 8 & 35 & 11 & 11 & 13 & 17 \\
\hline $2015 / 16$ & 5 & 33 & 9 & 9 & 11 & 15 \\
\hline $2016 / 17$ & 4 & 31 & 7 & 7 & 9 & 13 \\
\hline $2017 / 18$ & 3 & 30 & 7 & 8 & 9 & 13 \\
\hline 2018/19 & 4 & 39 & 11 & 11 & 11 & 18 \\
\hline $2019 / 20$ & 6 & 54 & 15 & 18 & 16 & 25 \\
\hline
\end{tabular}




\section{Homicide Victimisation Rate Per 100,000 for Age \\ Group 16-24, England and Wales 2008-2018}

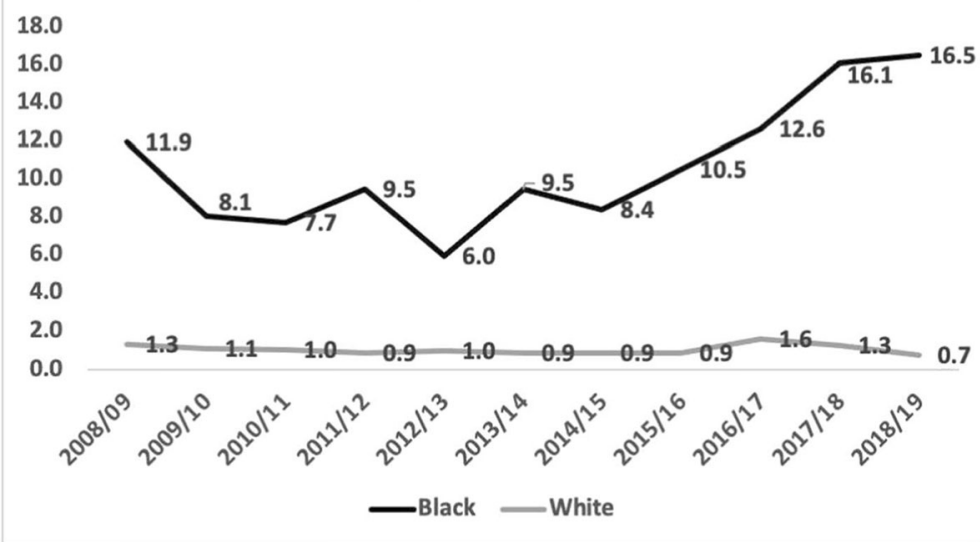

Fig. 1 (Source: Kumar et al. 2020)

people. What that means may depend on the kinds of crime, whether they are domestic or stranger, occurring on the street or behind closed doors. What is clear is that in the distribution of crime within most cities, the vast majority of the LSOAs would have far fewer than the mean number, which is pulled up by the extreme outliers (Sherman et al. 1989; Weisburd 2015).

Regrettably, we have no data for computing a midpoint (median) in the LSOAs for the annual number of serious violent crimes, since these data are not reported nationally at the LSOA level. Hence, we can only make estimates based upon prior studies. Using

Table 2 England and Wales 2019-2020 totals and rates of stops, serious violence, and lower super output areas

Total stop and search (SS) in England and Wales $=577,054$

Total serious violent crime (SVC) in England and Wales $=753,042$

Rate of stop and search to serious violent crime $(577,054 / 753,042)=0.77: 1$

(10 stops for every 13 serious violent crimes)

$N$ of lower super output areas (LSOA) $=34,753$

Mean of serious violent crimes per LSOA $=21.7$

Mean of stop and search per LSOA $=16.6$

\begin{tabular}{ll}
\hline Serious violent crimes (2019-2020) & Total \\
\hline Homicide & 683 \\
Death/serious injury caused by illegal driving & 696 \\
Violence with injury & 514,309 \\
Rape & 55,130 \\
Other sexual offences & 98,983 \\
Robbery of business property & 7972 \\
Robbery of personal property & 75,269 \\
Total serious violent crimes & 753,042 \\
\hline
\end{tabular}


Table 3 Dorset police ratio of stop and search to serious violent crime

\begin{tabular}{lll}
\hline Stop-search to serious violent crime ratio & LSOA $(N)$ & LSOA (\%) \\
\hline Less than E\&W Avg. (0.77) & 419 & $92.70 \%$ \\
Greater than E\&W Avg. (0.77) & 33 & $7.30 \%$ \\
Total & 452 & $100.00 \%$ \\
\hline
\end{tabular}

that method, we could say that only $5 \%$ of the LSOAs (1738) would have fully half of all the serious violent crimes in England and Wales $(376,521)$. The mean number of those crimes in those LSOAs would be $376.521 / 1738=217$ crimes, or 1 crime every 1.7 days (or every $40 \mathrm{~h}$ ) —in the "hottest" areas of the country.

This calculation is only an example. Yet it would mean that, in principle, concentrating deterrent policing (including stop and search) in that 5\% of LSOAs could not only, at best, cut violent crime in half. It could also justify a restriction on the use of stop and search in $95 \%$ of the LSOAs in England and Wales, home to some 57 million people (out of 60 million in England and Wales).

As a further example of how a tiered approach might suggest a threshold for using stop and search, the case of Dorset is helpful, since the Dorset Police offered their LSOA-specific data to the Cambridge Centre for analysis. Examining 4 years of their serious crime statistics across all 452 LSOAs in Dorset policing area (population = $700,000)$, how many of them had 217 serious violent crimes or more per year?

Three.

There were only three areas out of 452 that qualified as "national hot spots" of serious violent crime.

In other words, less than $1 \%$ of the 452 LSOAs in Dorset, which house over 700,000 people, exceed the national threshold of the $5 \%$ of all the 1738 LSOAs in England and Wales that would encompass over half of all serious violent crimes. The highest number of serious violent crimes was in an LSOA reporting 418 serious violent crimes in 2019-2020, or over one per day. The top three together produced over $12 \%$ of all serious violence in Dorset that year-and over $14 \%$ of all stop and search reports (Kumar et al. 2021). Even if we take the top $16 \%$, which had half of all the serious violent crimes in 2019-2020, it would leave $84 \%$ of the LSOAs in Dorset below a threshold of 26 serious violent crimes per year, or one serious crime every 2 weeks. The question for Dorset would be this: is that rate low enough to declare stop and search too much intrusion relative to the low risk of high crime harm?

Whether that much violence is sufficient to justify routine stops to prevent serious crime is not a decision that should be made by an algorithm. But it does suggest that most of these crimes may be concentrated in a few large forces-but only in a few high-risk areas of those large forces. Similarly, it suggests that stop and search may already be heavily concentrated in such areas - which raises questions about all the stops $95 \%$ of areas that do not have high concentrations of serious violent crime. It also implies that more stops may be needed in the highest crime "tier" for hot spots nationwide (Sherman, Three Tiers, forthcoming). 


\section{How Much Stop and Search Is Needed in Hot Spots vs. Elsewhere?}

The question of how the distribution of stop and search relates to the distribution of violent crime can be stated both descriptively and prescriptively. The descriptive question is this: how many stops do police undertake in relation to each serious violent crime? A poll of police professionals might reveal a wide range of guesses. But across England and Wales in 2019-2020, the answer was less than one (0.77 stops per serious violent crime). We do not know whether most of those stops were intended to prevent future crimes or to solve past crimes. We do not know the "hit rate." But we do know that most areas have far less serious violence than the areas in which stop and search has been tested and found effective against serious violence.

From the standpoint of prescription, the number of stops per violent crimes in previous experiments was far higher than the average in England and Wales. In the 200-day Kansas City Gun Experiment Sherman et al. (1995), for example, a 50\% reduction in "shots fired" crimes in a small beat ( 0.64 square miles) was achieved at a cost of intrusiveness summarized by Gladwell (2019: 307) as follows:

"1,090 traffic citations, 948 vehicle stops, 616 arrests, 532 pedestrian stops, and 29 guns seized...one police intervention every 40 minutes."

This total of over 3000 stops of people in public places - annualized at 5415 stops per year-was delivered after a prior-year history of 183 firearms-related crimes, including 8 murders. Even if we assume only one violent crime in 10 featured a firearm, that would still be 1830 crimes to 5415 stops, or 3 stops per serious violent crime in the prior year-four times the average rate in England and Wales. Prescriptively, then, what further research might demonstrate is the effectiveness of a strategy of many more police stops in many fewer places. Indeed, the benefit of a few stops a year in a low-crime LSOA might be zero, but the cost in anger at police intrusiveness could be very high indeed.

Even in Dorset, where the correlation between numbers of serious crimes and numbers of stops is very high $(R=.85)$, the vast majority $(93 \%)$ of LSOAs had fewer stops than the national average of .77 stops per serious violent crime (see Table 3). The prescriptive question of how to gain the greatest crime prevention effect from the same numbers of stops, if concentrated in higher-crime areas, remains unanswered.

\section{Tracking Risk-Adjusted Disparity in Very, Very Hot "Spots"}

Assigning police stops in fewer areas, but with many more stops in those selected areas, would entail many risks for both police and communities. The greatest risk is that there would be even more racial disparity in crime or intrusions than at present. The best defense against that risk is the use of a RAD Index to track the ratio of White to nonWhite stops per violent crime. If the RAD concept could be widely communicated and understood, it could become the foundation of a strategy for reducing the elevated risks of murder for non-Whites (relative to Whites), at least in the UK.

By measuring the ratio of White to non-White stops per violent crime, the RiskAdjusted Disparity (RAD) Index can be applied in any country in any context. In Japan, it could be used to examine potential over-policing of ethnic Koreans, relative to ethnic Japanese. In New Zealand, it could be used to compare policing of indigenous 
people relative to policing of persons of European origin. In the UK, it could be used to compare policing of Whites to any locally numerous minority groups, within and across police forces.

In all these settings, decennial Census data can provide measures of residential populations as the denominators. But that could be misleading. Resident populations are not the best measure of persons at risk of serious crime? Limited as they are, the numbers of violent crimes by race, rather than people by race, may be the best available measure.

\section{Limitations}

The major limitation of this approach to building a Risk-Adjusted Disparity (RAD) Index is well-documented in various reviews, notably two of them published by the National (US) Academies of Science (Skogan and Frydl 2004; Weisburd 2018). In order to estimate the actual risk of being stopped in public by police for any demographic, the best denominator is a demographic measure of people who are in public. As Ridgeway and MacDonald (2010: 6) noted:

"Given that the police are not likely to stop people at random, comparisons of racial distribution of stops to the residential population or the driving population on the roadways tells one very little about the race neutrality of the police. Again, it is necessary to establish a benchmark for the population at risk for official police contact. This means that one needs an accurate estimate of the subpopulation that is likely to elicit reasonable suspicion by the police."

Such measures, unfortunately, are extremely expensive. What is far less expensive is to measure the racial composition of the at-risk population for victimization on the basis of crime reports. Given the strong overlap between victimization and offending in highharm violent crimes, use of victimization provides a reliable (if not perfectly accurate) measure of the kinds of people who can be protected by police checking on them in high-violence areas at high-violence times.

Least Worst Solution Even acknowledging all the limitations, there is a case to be made for a victimization-based Risk-Adjusted Disparity (RAD) Index. The most powerful case is that it is better than no adjustment at all. It is not in the public interest of any democracy for its police force to be punished, reputationally, for trying to prevent murder and serious violence. As many parents of minority group murder victims have demanded, the disparity in murder rates requires even more stop and search - not less - in high violence areas of concentrated minority populations (and not in minority areas that lack high rates of violent crime).

Dialogue and Debate These ideas are complex and difficult to grasp at first reading or hearing. We have already presented them in a Webinar posted at https://www.youtube. com/watch? $\mathrm{v}=\mathrm{NbOBiUeqEW0}$, including a dialogue with senior police leaders in the UK concerned with violent crime and racial equity. Further discussions are planned, as well as research reports. These discussions are just a first step to further dialogue with community leaders, parents of victims of violence, and other local stakeholders - especially those in or near high-violence hot spots. They should not 
only include the RAD Index itself, but also the evidence that stop and search can save lives if it is highly focused in the right (few) places.

\section{Conclusion}

A risk-adjusted disparity (RAD) index is a tool that may or may not help to promote equal protection from serious violent crime. It is a tool that may, or may not, support the legitimacy of evidence-based efforts to fight against the illegitimate hierarchy of risks from violent crime. What it can do, with certainty, is to increase greater transparency in the process of making police policies and decisions that create intrusions on people's liberties in public places. To the extent that these intrusions can be shown to protect everyone equally - and especially those suffering the most intrusions - both democracies and their police may well become more sustainable.

Acknowledgements The authors would like to thank Chief Constable James Vaughan QPM of the Dorset Police for raising key questions and sharing key data used in this and other publications to promote more evidence-based discussion of stop and search policy. Comments from the $2021 \mathrm{M}$.St. students in the Police Executive Programme at the University of Cambridge also played a vital role in thinking through the concepts developed in this communication.

Funding This paper was prepared as part of a 2020 agreement for the Dorset Police to enroll over 25 analysts and police officers in short online courses on "Evidence-Based Policing of Serious Violent Crime" at the Cambridge Centre for Evidence-Based Policing Ltd. For further information on the courses, see https:// www.cambridge-ebp.co.uk/online-courses.

\section{Declarations}

Disclaimer The views stated herein are solely the views of the authors, and do not necessarily reflect the views of the Dorset Police or its leaders.

Lawrence W. Sherman is Director of the Cambridge Centre for Evidence-Based Policing Ltd. and Wolfson Professor of Criminology Emeritus at the University of Cambridge.

Sumit Kumar is a PhD student at the Jerry Lee Centre for Experimental Criminology at the Institute of Criminology, University of Cambridge, and a project manager at the Cambridge Centre for Evidence-Based Policing Ltd.

Open Access This article is licensed under a Creative Commons Attribution 4.0 International License, which permits use, sharing, adaptation, distribution and reproduction in any medium or format, as long as you give appropriate credit to the original author(s) and the source, provide a link to the Creative Commons licence, and indicate if changes were made. The images or other third party material in this article are included in the article's Creative Commons licence, unless indicated otherwise in a credit line to the material. If material is not included in the article's Creative Commons licence and your intended use is not permitted by statutory regulation or exceeds the permitted use, you will need to obtain permission directly from the copyright holder. To view a copy of this licence, visit http://creativecommons.org/licenses/by/4.0/.

\section{References}

Campana, P., \& Giovanetti. (2020). Predicting violence in Merseyside: A network-based approach using no demographic information. Cambridge Journal of Evidence-Based Policing, 4, 89-102. 
College of Policing (2020). Approved professional practice on stop and search. https://www.app.college. police.uk/app-content/stop-and-search/\#value-of-using-the-powers-appropriately

Crabtree, S. (2020) Most Americans say policing needs 'major changes' Gallup News. July 22. https://news. gallup.com/poll/315962/americans-say-policing-needs-major-changes.aspx

Cutler, A. (2020). Dorset Police more likely to stop and search black people. Dorset Echo June 10. https:// www.dorsetecho.co.uk/news/18506564.dorset-police-likely-stop-search-black-people/ downloaded on 17 January 2021

Demirjian, K., Davis, A, Hermann, P. (2021). Acting Capitol Police chief apologizes to lawmakers for 'failings' that allowed Jan. 6 breach. Washington Post, 27 January. https://www.washingtonpost.com/ politics/capitol-police-apology/2021/01/26/9d8ca5da-5ffe-11eb-9061-07abcc1f9229_story.html

Dorset Police (2020) Stop and search figures-statement. 08 June. https://www.dorset.police.uk/newsinformation/article/10226

Gladwell, M. (2019). Talking to strangers. Allen Lane.

Hiltz, N., Bland, M., \& Barnes, G. C. (2020). Victim-offender overlap in violent crime: Targeting crime harm in a Canadian suburb. Cambridge Journal of Evidence-Based Policing, 1, 11.

Home Office. (2014). PACE CODE A: Revised Code of Practice for the exercise by: Police Officers of Statutory Powers of stop and search. TSO.

Kumar, S., Sherman, L. W., \& Strang, H. (2020). Racial disparities in homicide victimisation rates: How to improve transparency by the Office of National Statistics in England and Wales. Camb J Evid Based Polic, 4, 178-186. https://doi.org/10.1007/s41887-020-00055-y.

Kumar, S., Sherman, L., Lyne, S. and Vaughan, J. (2021). Tracking stop and search in Dorset using a RiskAdjusted Disparity (RAD) Index for over- and under-policing of violence against minority groups. Forthcoming in Camb J Evid Based Polic.

Lattimore, P. K., Linster, R. L., \& MacDonald, J. M. (1997). Risk of death among serious Young offenders. Journal of Research in Crime and Delinquency, 34(2), 187-209.

Massey, J., Sherman, L. W., \& Coupe, T. (2019). Forecasting knife homicide risk from prior knife assaults in 4835 local areas of London, 2016-2018. Camb J Evid Based Polic, 3, 1-20. https://doi.org/10.1007/ s41887-019-00034-y.

Office of National Statistics, United Kingdom (2020). Stop and search. https://www.ethnicity-facts-figures. service.gov.uk/crime-justice-and-the-law/policing/stop-and-search/latest

Reiss, A. J., \& Roth, J. (1993). Understanding and preventing violence: 1. Washington, DC: the National Academies Press. https://doi.org/10.17226/1861.

Rice, S, White, M (n.d.) Race, ethnicity, and policing: New and essential readings (180-204).

Ridgeway, G. \& MacDonald, J. (2010). Methods for assessing racially biased policing.

Sandall, D., Angel, C. M., \& White, J. (2018). 'Victim-offenders': A third category in police targeting of harm reduction. Cambridge Journal of Evidence-Based Policing, 2(3), 95-110.

Sherman, L. W., Gartin, P. R., \& Buerger, M. E. (1989). Hot spots of predatory crime: Routine activities and the criminology of place. Criminology, 27(1), 27-56.

Sherman, L. W., Shaw, J. W., \& Rogan, D. P. (1995). The Kansas City Gun Experiment. US Department of Justice.

Sherman, L. (n.d.) forthcoming. Three Tiers for Evidence-Based Policing: Minimalist Policing with a RiskAdjusted Disparity Index. Chapter 2 In D. Weisburd, T. Jonathan, B. Hasisi \& G. Perry. Evidence-Based Policing. Cambridge: Cambridge University Press.

Simpson, J. (2020). Jeremy Meneses-Chalarca: Machete victim's family demand more searches. The Times. August 11. https://www.thetimes.co.uk/article/jeremy-meneses-chalarca-machete-victims-familydemand-more-searches-qkpj3rb19 Downloaded 21 February 2021.

Sklansky, D. A. (2004). Police and democracy. Mich. L. Rev., 103, 1699.

Sklansky, D. A. (2008). Democracy and the police. Stanford University Press.

Skogan, W., \& Frydl, K. (2004). National Research Council Report on Fairness and effectiveness in policing: The evidence. In Committee to review research on police policy and practices, Committee on Law and Justice, Division of Behavioral and Social Sciences and Education. The National Academies Press.

Unnever, J. D., Stults, B. J., \& Messner, S. F. (2021). Structural racism and criminal violence: An analysis of state-level variation in homicide. Race and Justice, 21533687211015287.

Weinborn, C (2017). From Hotspots to Harmspots, an empirical exploration of crime concentrations and crime harm in the United Kingdom. Ph.D. dissertation, Institute of Criminology, University of Cambridge.

Weisburd, D. (2015). The law of crime concentration and the criminology of place. Criminology, 53(2), 133157. 
Weisburd, D., \& Majmundar, M. (2018). National Academies of Sciences, Engineering, and Medicine. Proactive policing: Effects on crime and communities. The National Academies Press https://doi.org/ $10.17226 / 24928$.

Wilson, J. Q. (1978). Varieties of police behavior: The management of law and order in eight communities, with a new preface by the author. Harvard University Press.

Wolfgang, M., \& Wolfgang, M. E. (1958). Patterns in criminal homicide. University of Pennsylvania Press. Zimring, F. E. (2017). When police kill. Harvard U. Press.

Publisher's Note Springer Nature remains neutral with regard to jurisdictional claims in published maps and institutional affiliations. 